\title{
AC 2010-1841: CLEERHUB.ORG: CREATING A DIGITAL HABITAT FOR ENGINEERING EDUCATION RESEARCHERS
}

\section{Ruth Streveler, Purdue Universtiy}

Ruth A. Streveler is an Assistant Professor in the School of Engineering Education at Purdue University. Before coming to Purdue she spent 12 years at Colorado School of Mines, where she was the founding Director of the Center for Engineering Education. Dr. Streveler earned a BA in Biology from Indiana University-Bloomington, MS in Zoology from the Ohio State University, and Ph.D in Educational Psychology from the University of Hawaii at M?noa. Her primary research interest is investigating students' understanding of difficult concepts in engineering science.

\section{Alejandra J. Magana, Purdue University, West Lafayette}

Alejandra J. Magana is a postdoctoral research fellow at the Network for Computational Nanotechnology and the School of Engineering Education, at Purdue University West Lafayette. Alejandra's research interests center on how scientists and engineers reason with computing and computational thinking to understand complex phenomena. She is also interested in investigating how scientists and engineers perceive and experience the societal and ethical implications of nanotechnology. Based on her findings her goal is to identify and develop the necessary instructional changes to provide educational frameworks for educators of formal and informal learning environments.

\section{Karl Smith, University of Minnesota}

Karl A. Smith is Cooperative Learning Professor of Engineering Education, School of Engineering Education, at Purdue University West Lafayette. He has been at the University of Minnesota since 1972 and is in phased retirement as Morse-Alumni Distinguished Professor of Civil Engineering. He has been actively involved in engineering education research and practice for over thirty years. He is a Fellow of the American Society for Engineering Education and past Chair of the Educational Research and Methods Division. Karl has worked with thousands of faculty all over the world on pedagogies of engagement, especially cooperative learning, problem-based learning, and constructive controversy. He has co-written eight books including How to Model It: Problem Solving for the Computer Age, Active Learning: Cooperation in the College Classroom, 3rd Ed., Cooperative learning: Increasing college faculty instructional productivity; Strategies for energizing large classes: From small groups to learning communities; and Teamwork and project management, 3rd Ed.

\section{Tameka Clarke Douglas, Purdue University}

Tameka Clarke Douglas is a doctoral candidate in Purdue's School of Engineering Education. Her research interests include communities of practice and conceptual understanding in statics. 


\title{
CLEERhub.org: Creating a digital habitat for engineering education researchers
}

\begin{abstract}
CLEERhub.org uses HUBzero architecture to create a digital habitat for engineering education researchers. Wenger has stressed that community needs should be explored before a digital habitat is created. With this in mind, this paper discusses the features of CLEERhub envisioned by a sample of engineering education researchers. These features are mapped to three polarities Wenger identified as existing within virtual communities. Features which allow for asynchronous connections are favored by this sample of the engineering education research community and will be emphasized in the development of CLEERhub.

Introduction

In 2004, the National Science Foundation sponsored three projects to build capacity in engineering education research: Rigorous Research in Engineering Education: Creating a Community of Practice (RREE) [DUE-0341127], Strengthening HBCU Engineering Education Research Capacity, [HRD0411994], and the Institute for Scholarship in Engineering Education (ISEE), an element of the Center for the Advancement of Engineering Education [ESI-0227558]. These programs attracted tremendous interest, with participant applications outweighing available slots by a ratio of approximately 3 to 1 . The engineering education research communities that RREE and ISEE helped to foster have expanded and now have global reach. Capacity building has also been aided by the creation of PhD-granting departments of Engineering Education at several US and international institutions.
\end{abstract}

NSF recently funded a new project to continue and expand the work done by RREE and ISEE. Expanding and sustaining research capacity in engineering and technology education: Building on successful programs for faculty and graduate students (which we will call the RREE2) (DUE0817461) broadens the Community of Practice (COP) model successfully used to develop the RREE and ISEE programs. 
The RREE2 project has three goals:

1. Design and deliver a new generation of programs to educate engineering and engineering technology faculty and graduate students that are effective, flexible, inclusive, and sustainable after funding ends.

2. Foster a virtual community of engineering and engineering technology education researchers through the use of Purdue HUBzero technology

3. Conduct evaluation on impact of these programs on individuals who participate and on the respondents' students and institutions.

This paper addresses the second goal of the RREE2: fostering a virtual community of engineering and engineering technology education researchers. In particular, we will discuss the design and development of the Collaboratory for Engineering Education Research (CLEERhub.org) and map the design of this virtual space to the community of practice model.

CLEERhub.org uses HUBzero architecture. HUBzero was originally created by researchers of the Hub Technology Group at Purdue University in conjunction with the NSF-sponsored Network for Computational Nanotechnology to support nanoHUB.org. HUBzero [see http://hubzero.org/] is a platform used to create dynamic web sites for scientific research and educational activities by offering an organized collection of tools and resources. This platform has capabilities that support scientific discovery, learning, and collaboration. ${ }^{1}$ CLEERhub is used in the RREE2 to provide an archive of critical engineering education information and to expand the engineering education Community of Practice.

A Community of Practice (COP) is comprised of three elements: a domain of knowledge, which is defined by a set of issues; a community of people who care about this domain; and the shared practice that they are developing to be effective in their domain. ${ }^{2}$ Etienne Wenger, who coined the term "community of practice" has recently presented a new model for creating virtual communities of practice and it is his work "Digital Habitats: Stewarding Technology for Communities" that provides the framework for this paper. ${ }^{3}$

Wenger and colleagues [3] propose that there are three inherent polarities that present challenges in creating and sustaining a virtual community. These three polarities are: 
- Rhythms: togetherness and separateness

- Interactions: participation and reification

- Identities: individual and group.

These three polarities are represented by Wenger in the following figure.

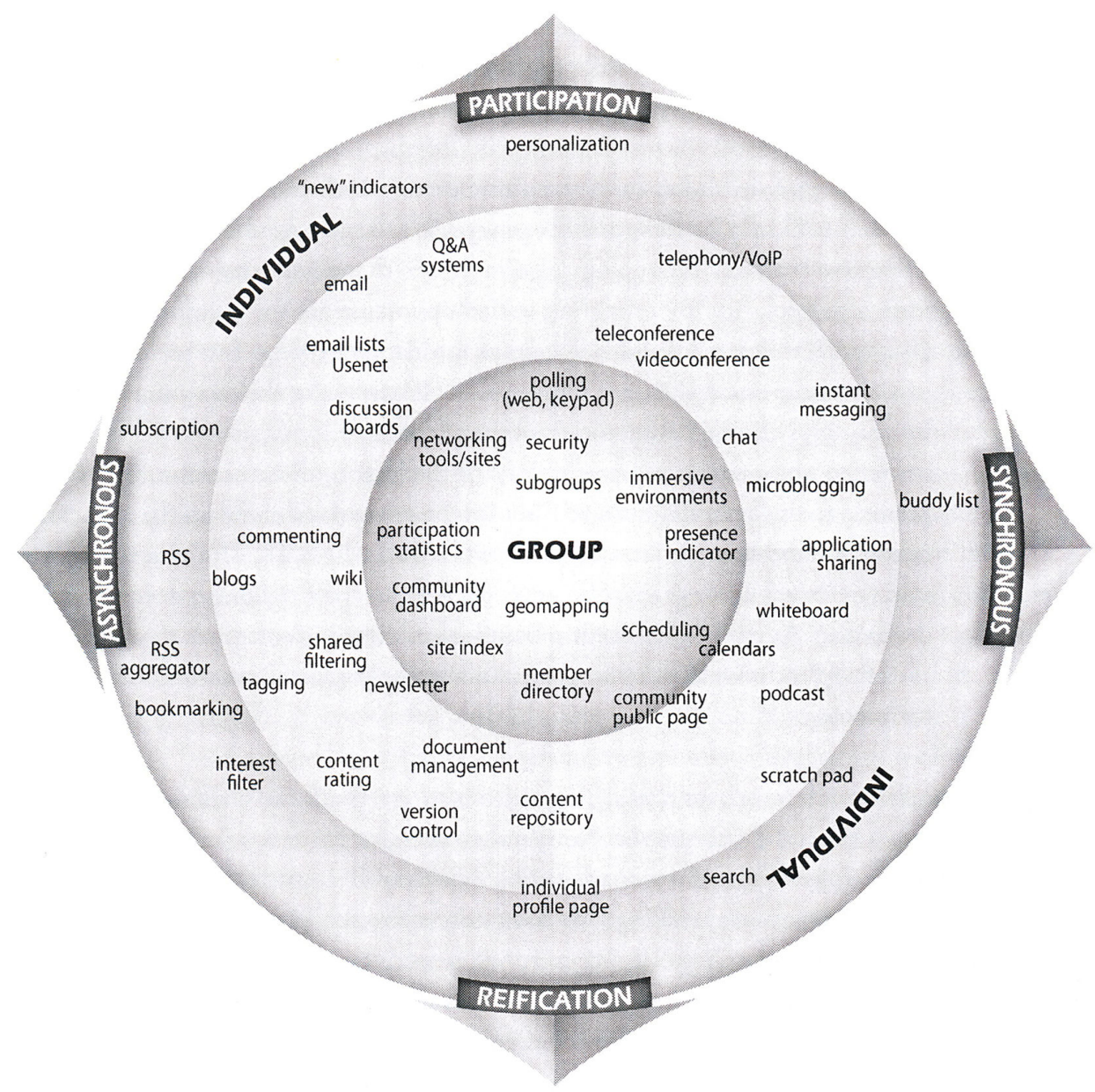

Figure 1. Representation of tools used by virtual communities mapped into Wenger's three polarities. From ${ }^{3}$, p. 60 . 
Wenger also stresses that before building a virtual community of practice, one must assess the needs of the community. With this in mind, we posed the following research question:

- How should the features of CLEERhub map to Wenger' community of practice model?

Methods

\section{Respondents}

In order to answer our research question, we drew up a list of people we felt were both familiar with virtual environments and experienced engineering education researchers. In order to diversity possible viewpoints, the list included people from the US and beyond who worked at a variety of institution types. Potential respondents were sent an email invitation to provide feedback about CLEERhub. Six respondents accepted the invitation and completed the online survey.

\section{Data Collection Method}

A needs assessment for CLEERhub was completed using Qualtrics software to create an online survey. The following questions were posed, with text boxes available for open-ended responses.

- If you were using CLEERhub to connect with people, what features of the site would you need or want?

- If you were using CLEERhub to connect with resources, what features of the site would you want or need?

O What would motivate you to use a site like CLEERhub?

- What features or aspects of CLEERhub would motivate other people to visit? (What do you feel would bring people to the site?)

o What would make a site like CLEERhub user-friendly?

○ Do you have other suggestions or comments? 
Grounded Theory was employed as the methodological framework to analyze the data Strauss and Corbin. ${ }^{4}$ Through Grounded theory identified themes and findings emerged directly from the data. The process of inductive analysis consisted of a process of identification of differences and similarities in the data, resulting in a set of categories or themes and their properties and interrelations. ${ }^{5}$ Using these approaches we investigated how features of Wenger's community of practice model could be adopted as part of CLEERhub. In particular, we sought to determine how respondents' needs for expanding and sustaining research capacity in engineering and technology education could be served through an effective digital habitat.

Results

In general, participants pointed out that they would use CLEERhub when they have the need to look for specific information, either specific content or a specific person with expertise in a particular research topic. They also wanted to have from CLEERhub the value added of providing unique information in engineering education and educational research, in an organized way, not available from other resources. For example, information about: a) other people, their research interest, and their groups or affiliations within and outside the website, b) recent developments of the field, c) grant opportunities, and d) research methodologies.

"I would probably only use it if I were looking with a specific purpose in mind. I would probably not go there just to hang out on a discussion board or chat room."

"Regularly updated information of immediate relevance and utility that is not available from other sources."

"If it were an easy to use, one-stop site for finding information on engineering education. If it were set up well, I could easily see it as being the first place I go to when I am searching for information or people." 
Important features and characteristics of CLEERhub respondents pointed out as important can be summarized in a quick and clear way to search and access this information. These include clear navigation structure with clear menus including a site map, appealing layout with information well distributed and consistent throughout the entire site, clear language, easy access to resources, easily manageable and searchable and memory of recent searches, easy way to locate contact information of site administrator/webmaster, short page loading time, regular site updates based on users' feedback

\begin{abstract}
"Although the structure and features of the HUB could be very sophisticated, keeping things simple would make users more comfortable, particularly the ones with less experience. I would suggest perform site usability tests periodically."
\end{abstract}

"Clean and un-cluttered layout... no acronyms - none!"

"Good user interface. Keep it simple. Keep it strong."

Another aspect respondents considered important was to experience a sense strong of participation from the community.

"Strong participation from the community. Liveliness"

Equally important, they wanted to know that support is always available. Wenger and colleagues pointed out that having a community coordinator was essential for sustaining a Community of Practice. $^{2}$ Respondents validated this need in their comments. So having a community coordinator to keep things going was still deemed necessary.

"Knowing there will be someone there. Who will nurture/foster the growth/participation of users?" 
Considering the activities and tools of "community orientations" proposed by Wenger, White and $\mathrm{Smith}^{3}$ as a framework for analyzing user requirements, we can identify three main themes related to community, networking, and content.

\section{Community cultivation, access to expertise and relationships}

Respondents showed their interest to have the ability to search and see other people's research interest and be able to contact them, including a section in members of the community could be featured on a regular basis.

"So the ability to search profiles of people in engineering education to identify specific expertise I am looking for, or a way to send a broadcast email asking for responses to a specific inquiry."

“...users could easily locate their potential intellectual peers. Perhaps a section featuring members of the community on a regular basis."

\section{Meetings, open ended conversations and projects}

Respondents wanted to interact with other people in order to have discussions about specific topics based on their interests

"Spaces devoted specifically to a topic (e.g. K-12, diversity, assessment), where subgroups of users were aggregated based on their interests, and new users could easily locate their potential intellectual peers. “

"An extremely well organized database with capabilities similar to wikis that allow users to collaborate in the creation/edition of documents Perhaps a way to know 'what is new' on the site since my last visit." 
"Threaded conversations, perhaps with tags, so that folks could join in, catch up, add to .... as inspired."

\section{Content}

Respondents also pointed out that well-organized content with searching capabilities would be very useful features. Other capabilities mentioned for content sharing were ability to write, edit and share files collaboratively, share multiple resources such as endnote libraries, also automatic suggestion of similar papers, similar contributed entries, and other related resources.

"...I would look for resources with a specific need in mind. So the ability to search the resources easily to find what I am looking for. The types of resources would probably be papers, book chapters, or books on a specific topic or methodology." "listing of funding sources with information on the things that they are likely to fund..."

\section{Discussion}

Returning to Figure 1, one can see that features of CLEERhub identified in the needs assessment were concentrated on the "asynchronous" side of the graphic. This suggests that the respondents were less interested in real-time connections with others.

In general, most of the respondents focused their responses in terms of services and content they would like to receive from the website. Features of the website that respondents identified the most important and useful were the search of people and content and a userfriendly navigation.

The most common response for reasons for accessing the website was related to needs of accessing or searching specific information and people and not to "hang out". Therefore, none of the respondents saw the potential of CLEERhub to provide in-depth interaction with other researchers and to have access to community cultivation. Furthermore, none of the respondents commented on the possibility of contributing content to the site although they pointed out the 
need for strong participation from the community. This desire for a community without the mention of contributing to the community can be viewed as a somewhat paradoxical result and deserves more investigation. It is possible that the notion of building CLEERhub by contributing content, rather than just passively viewing the content is new to the respondents and this might account for the reason it was not mentioned. It is also possible that the questions we posed in the online survey may have not prompted that thought in the respondents. Moving people from just accessing information to taking part in knowledge-building could a challenge we will have to address. However, more research will be needed to confirm these results. Face-to-face interviews, which allow for follow-up questions and prompts, may be a more appropriate way to obtain a true picture of people's attitudes about community building. Respondents were also asked to think about CLEERhub theoretically, before they were actually able to view a prototype. Now that CLEERhub is operational, its community building potential may be more obvious to those who visit the site. 


\section{References}

[1] HUBzero (2009). Platform for scientific collaboration created by Purdue University. Last retrieved on January 1, 2010 from: http://hubzero.org/about

[2] Wenger, E., McDermott, R., \& Snyder, W. (2002). Cultivating communities of practice. Cambridge, MA: Harvard Business School Press.

[3] Wenger, E., White, N., \& Smith, J.D. (2009). Digital habitats: Stewarding technology for communities. Portland, OR: CPSquare Press.

[4] Strauss, A., \& Corbin, J. (1990). Basics of qualitative research: Grounded theory, procedures, and techniques. Newbury Park, CA: Sage.

[5] Glaser, B., Strauss, A., (1967). The discovery of grounded theory: Strategies for qualitative research. Chicago, IL: Aldine. 